\title{
Discounting and the environment
} should current impacts be weighted differently than impacts harming future generations?

\author{
Journal Article \\ Author(s): \\ Hellweg, Stefanie (1); Hofstetter, Thomas B.; Hungerbühler, Konrad \\ Publication date: \\ 2003 \\ Permanent link: \\ https://doi.org/10.3929/ethz-b-000423082
}

Rights / license:

In Copyright - Non-Commercial Use Permitted

Originally published in:

The International Journal of Life Cycle Assessment 8(1), https://doi.org/10.1007/BF02978744 


\title{
LCA Methodology with Case Study
}

\section{Discounting and the Environment}

\section{Should Current Impacts be Weighted Differently than Impacts Harming Future Generations?}

\author{
Stefanie Hellweg“, Thomas B. Hofstetter and Konrad Hungerbühler \\ Swiss Federal Institute of Technology Zurich, Chemical Engineering Department, Safety and Environmental Technology Group, \\ ETH-Hönggerberg, HCI G129, CH-8093 Zurich, Switzerland
}

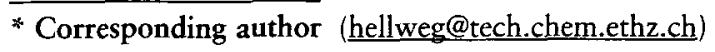

DOI: http://dx.doi.org/10.1065//ca2002.09.097

\section{Abstract}

Background. In Life-Cycle Assessment (LCA), decision makers are often faced with tradeoffs between current and future impacts. One typical example is waste incineration, where immediate emissions to the air from the incineration process have to be weighted against future emissions of slag landfills. Long-term impacts are either completely taken into account or they are entirely disregarded in case of a temporal cut-off. Temporal cutoffs are a special case of discounting.

Objective. In this paper, discounting is defined as valuing damages differently at different points of time using a positive or negative discount rate. Apart from temporal cut-offs, discounting has rarely been applied in LCA so far. It is the goal of this paper to discuss the concept of discounting and its applicability in the context of LCA.

Methods. For this purpose, we first review the arguments for discounting and its principles in economic sciences. Discounting in economics can be motivated by pure time preference, productivity of capital, diminishing marginal utility of consumption, and uncertainties. The nominal discount rate additionally includes changes in the price level. These arguments and their justification are discussed in the context of environmental impacts harming future generations.

Results and Discussion. It is concluded that discounting across generations because of pure time preference contradicts fundamental ethical values and should therefore not be applied in LCA. However, it has to be acknowledged that in practice decision makers often use positive discount rates because of pure time preference - either because they might profit from imposing environmental damage on others instead of themselves or because people in the far future are not of immediate concern to them. Discounting because of the productivity of capital assumes a relationship between monetary values and environmental impact. If such a relationship is accepted, discounting could be applied. However, future generations should be compensated for the environmental damage. It is likely that they would demand a higher compensation if the real per capita income increases. As both the compensation and the discount rate are related to economic growth, the overall discount rate might be close to zero. It is shown that the overall discount rate might even be negative considering that the required compensation could increase (even to infinite) if natural assets remain scarce, whereas the utility of consumption diminishes with increasing income. Uncertainties could justify both positive and negative discount rates. Since the relationship between uncertainties and the magnitude of damage is generally not exponential, we recommend to model changes in the magnitude of damage in scenario analysis instead of considering it in discounting (which requires an exponential function of time in the case of a constant discount rate). We investigated the influence of discounting in a case study of heavy metal emissions from slag landfills. It could be shown that even small discount rates of less than $1 \%$ lead to a significant reduction of the impact score, whereas negative discount rates inflate the results.

Conclusions and Recommendations. Discounting is only applicable when temporally differentiated data is available. In some cases, such a temporal differentiation is necessary to take sound decisions, especially when long emission periods are involved. An example is the disposal of nuclear or heavy metal-containing waste. In these cases, the results might completely depend on the discount rate. This paper helps to structure arguments and thus to support the decision about whether or not discounting should be applied in an LCA.

Keywords: Discounting; discount rate; externalities; landfill; LCA; LCIA; long-term impacts; monetarization; scenario; time dependency; time preference; values; weighting

\section{Introduction}

It has long been recognized that certain environmental decisions involve tradeoffs between present and future impacts. Such tradeoffs raise issues of (intergenerational) fairness and equity that are ethical in nature. Life-Cycle $\underline{\text { Assessment (LCA) }}$ involves many of such temporal issues [1]. For instance, construction materials are often 'stored' in buildings for many decades before they are recycled or disposed of [2]. It is uncertain, which disposal technologies will be used for these materials in the future. Information about the composition of materials might be lost in the course of the years, which makes an adequate treatment more difficult. The use of some of these materials or substances with a high impact or risk potential might have even been forbidden or limited meanwhile (e.g. CFC), but they remain to be released to the environment for long times. Resources are bound in the building that cannot be used for other purposes. While the initial 
use of resources is usually considered in LCA, the time period of use is neglected [2]. Moreover, when materials are recycled, impacts are generally not allocated to the secondary product in LCA. Finally, some of the emissions, e.g. from land-filling construction residues, occur in the far future and it is unclear how they should be assessed.

In general, LCA makes no explicit differentiation between emissions (and, ultimately, impacts and damages) at different points in time. For instance, whether an emission contributes to ozone depletion today or in 200 years is treated equally in LCA. Nevertheless, there are some forms of implicit discounting that are common practice, e.g. temporal system boundaries [3]. Temporal cut-offs are a special case of discounting with a discount rate of zero for the time horizon considered and of infinity thereafter. Such temporal system boundaries are often proposed for landfill emissions $[4,5]$. Similarly, the distinction between short-term emissions ( $\leq 100$ years) and long-term emissions ( $>100$ years) $[6,7]$ implies a different valuation for the two periods. In the impact assessment phase, the choice of several models is related to time. For instance, different time horizons can be chosen for the global warming effect, typically 20,100 , and 500 years. Depending on this choice, the global warming potential of a pollutant may differ considerably. Huijbregts et al. [8] found that metal toxicity potentials differed up to 6.5 orders of magnitude depending on the time horizon chosen in the fate model. These large differences are due to long residence times and slow removal pathways from the soil and marine water/sediment compartments. To reduce the importance of long-term emissions, several methods introduced fictitious 'removal rates' or 'degradation rates' for metals in the fate modeling, (another example of implicit discounting) $[9,10]$. Despite these examples, and in contrast to other projects such as the Impact Pathway Method of the ExternE Project ${ }^{1}$ [12], explicit discounting has rarely been applied in LCA (exceptions are $[13,14]$ ). Since LCA is a valuebased decision support tool, it needs to address time-preferences if they are relevant in the context of future environmental damages. There are some applications such as waste incineration, where tradeoffs between impacts in the present and in the future have to be made. For instance, new thermal waste treatment technologies prevent long-term emissions at the cost of a higher energy use with more immediate impacts. These issues demand a thorough discussion of whether impacts at different points in time should be weighted alike and, therefore, whether discounting (including temporal system boundaries) should be applied in LCA.

In this paper, we briefly introduce the economical background of discounting (Section 1). Emphasis is placed on motivating the use of discounting in LCA (Section 2) and on illustrating the consequences of discounting in a case study (Section 3). It is neither the intention of this paper to discuss all ethical standpoints involved (see [3] for an overview) nor to provide a universal answer of whether or not discounting

1 Although the Impact Pathway methodology has not been designed for LCA purposes, it is very similar and could be part of an LCA [11]. should be applied in the context of LCA. An anthropocentric point of view is adopted throughout the whole paper (as is always the case in economic discounting). Furthermore, it is assumed that weighting between different environmental impacts, as often performed in quantitative LCA, is not perceived as 'unethical'. Otherwise, weighting environmental damages at different points of time is certainly also not accepted so that the following discussion would be needless.

\section{The Concept of Discounting: Economical Background}

In the economic sciences, future costs and benefits are usually discounted to a present value in order to make them comparable to current costs and benefits (cost/ benefit analysis) [15]. There are several reasons for valuing one monetary unit of benefit or cost differently at different points of time. For instance, pure time preferences (impatience), the productivity of capital (related to economic growth / decline), and uncertainty / risk perception are all factors that change valuations with time. The way the valuation changes in time is generally known as the discount rate. This rate depends on the factors just mentioned. Thus, in economics, the Net Present Value (NPV) of an investment is calculated as a function of benefits, costs, and the discount rate (Equation 1):

$$
N P V=\sum_{t=0}^{T}\left(\left(B_{t}-C_{t}\right) * \frac{1}{(1+r)^{t}}\right)
$$

Where $B$ represents the benefits, $C$ the costs, $r$ is the discount rate, and $t$ is a time index. The discount rate of Equation 1 is expressed in real terms, net of any changes in the price level. To give an example, a Euro invested today at an interest rate of $5 \%$ will have increased to 11.47 Euros in 50 years. Conversely, 100 Euros in 50 years would be worth (would require investing) 8.72 Euros now. This latter amount of money represents the NPV.

In economics, the choice of the discount rate is controversially discussed especially when investments in the public sector are at stake [16-18] or if the durations considered are long. This discussion involves the question whether the private or the social discount rate should be taken. The private discount rate can be observed on the financial markets; for instance, a typical value would be between 5 and $7 \%$ per year in the European Union [12]. Many companies, however, calculate with private discount rates greater than $10 \%$. The social discount rate can be defined as the interest rate at which society is willing to lend money for public projects [15] (Equation 2):

$$
r=r_{p r e f}+\eta^{*} r_{g r o}
$$

Where $r_{\text {pref }}$ is the pure rate of time preference (accounting for impatience), $r_{\text {gro }}$ rate of economic growth (growth of the Gross $\underline{N}$ ational Product, GNP), and $\eta$ the negative of the elasticity of the marginal utility of consumption. The marginal utility of consumption decreases with increasing income. For a family living at the poverty level, for instance, an additional Euro income is assumed to have a higher utility than for a millionaire. The elasticity of the marginal utility of consumption is 
negative, and $\eta$ therefore has a positive value $(\eta$ is generally given as between 1 and $3[15,18,19])$. The component $\eta{ }^{*} r_{\text {gro }}$ thus accounts for the idea that societies will probably be richer in the future (assuming economic growth) and that we should attach less weight to their gains.

In an ideal economy the social and private discount rate of the financial market should be the same $[15,18]$. However, the social discount rate is usually smaller than the private discount rate. Some of the reasons are that private companies have to pay taxes for their benefits and that public projects are thought to be less risky than private projects [15]. Note that the discount rate is not necessarily constant, although it is generally assumed to be so in practice. In fact, if future interest could be accurately predicted, cost-benefit theory would then recommend the use of these differing rates [20]. However, only few economic models calculate with non-constant discount rates [21].

\section{Discounting and the Environment: Motivations and Objections}

This section discusses a possible transfer of the discounting principle to environmental projects and LCA. As mentioned above, discounting in economics takes into consideration:

1. Changes in the price level (only nominal discount rate);

2. Pure time preference;

3. Productivity of capital and diminishing marginal utility of consumption;

4. Uncertainties.

These four arguments for discounting will be discussed one by one in Sections 2.1 to 2.4. First, the authors will generally discuss the justification of these motivations in the context of LCA. In a second step, we suggest possible consequences for the discount rate. In the present study, the 'European' perspective of LCA is adopted, which permits the aggregation of environmental impacts [22] and thereby allows comparing damages of different nature.

\subsection{Changes in the magnitude of impact}

In economics, the nominal discount rate includes changes in the price level. With respect to LCIA, changes in the environment might lead to a change in value of the unit measuring the damage (monetary or not). For instance, an accumulation of heavy metals in the environment might trigger a change in the damage produced by an additional unit of emission. If these changes have not been considered in an earlier phase of the impact assessment, the measuring unit is subject to inflation or deflation, because it no longer corresponds to the same magnitude of damage. A 'nominal' discount rate would include such changes in the magnitude of damage. Thus, using a 'real' discount rate $^{2}$ requires considering changes in damage magnitude in the impact assessment prior to discounting.

The modeling of changes in the magnitude of impact as a function of space and time appears to be widely accepted. Potting et al. [25] suggest different site-dependent acidification factors for 44 regions in Europe for the years 1990 and 2010. Similarly, the ISO-norms state with respect to normalization that the selection of the reference system should consider the consistency of the spatial and temporal scales of the environmental mechanisms and the reference value [26]. The magnitude of an impact might change, for instance, as a consequence of a changing background concentration of a pollutant or pollutant mix in the environment (Table 1). The relation between concentrations in the environment and dam-

\footnotetext{
2 Rabl [24] applied a similar concept to calculate an 'effective discount rate' in the case of nuclear energy. He considered a change in the magnitude of damage by considering improvement of medical treatment and the increasing number of cancer cases due to increases in life expectancy. $\mathrm{He}$ assumes that the number of cancer cases and medical advances evolve exponentially. Based on past data (reduction of fatalities per case of cancer in 100 years and increase in cancer rate by $18.9 \%$ in 23 years), he concludes that the real discount rate should be close to zero [24].
}

Table 1: Examples illustrating possible motivations for discounting in LCA

\begin{tabular}{|c|c|}
\hline $\begin{array}{l}\text { Motivation for } \\
\text { discounting }\end{array}$ & Example \\
\hline $\begin{array}{l}\text { 1. Changes in the } \\
\text { magnitude of damage }\end{array}$ & $\begin{array}{l}\text { The background concentration of pollutants in the environment changes as a function of time. Assuming non-linear } \\
\text { concentration-effect-curves, the magnitude of impact would change as well. Consequently, the future impact of an } \\
\text { emission would be different than its current impact. }\end{array}$ \\
\hline 2. Pure time preference & $\begin{array}{l}\text { Two technologies release the same amount of an emission, but at different points in time. Technology A releases } \\
\text { this emission today, technology } B \text { in } 100 \text { years. In both cases, this emission will have the same impact on the } \\
\text { environment. Discounting because of pure time preference would mean that technology B would be preferred to } \\
\text { technology } A \text {, in spite of the equivalence in impact. }\end{array}$ \\
\hline 3. Productivity of capital & $\begin{array}{l}\text { - Prevention costs: Imagine a landfill that does not release major emissions in the first } 200 \text { years and from which } \\
\text { heavy metals could be extracted and recycled today or in } 200 \text { years for the same price of } 1 \text { million Euros (thus } \\
\text { preventing emissions). Assuming a discount rate of } 2.3 \% \text { (average growth in Switzerland from 1910-1967 } \\
{[23] \text { ), it would be sufficient to invest } 11,000 \text { Euros on the capital market today in order to finance the project in }} \\
200 \text { years. } \\
\text { Damage compensation: Assume that environmental damages can be compensated financially. Using the } \\
\text { above example, it would be sufficient to invest } 11,000 \text { Euros on the capital market in order to pay a } \\
\text { compensation of } 1 \text { million Euros in } 200 \text { years. }\end{array}$ \\
\hline 4. Uncertainties & $\begin{array}{l}\text { - A toxic emission does not have its impact because humankind (the environment, the earth) does not exist any } \\
\text { more (reasoning for a positive discount rate). } \\
\text { - The population number increases and thereby the number of effected people (reasoning for a negative } \\
\text { discount rate). } \\
\text { - A technology will be developed to prevent all damages (reasoning for a positive discount rate). }\end{array}$ \\
\hline
\end{tabular}




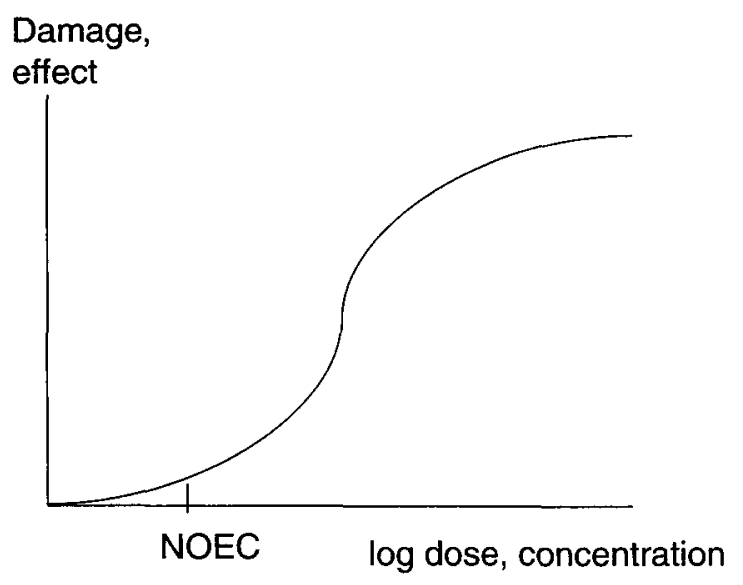

Fig. 1: Sigmoid concentration / effect or damage curve [28] (NOEC: NoObserved Effect Concentration). The effect depends on the dose (in general, the dose is related to the concentration of a pollutant or pollutant mix in the environment). Aggregating LCIA methods use the slopes of the damage curves as weighting factors

age is often illustrated in concentration-effect or damage curves. These curves generally have a sigmoid shape (Fig. 1).

If the background contamination level changes, the position on the damage curve and the slope will change as well. Aggregating LCIA methods use these slopes as weighting factors. Therefore, it is important to know the present and future positions on the damage curves in order to estimate the potential impact or damage of the system under study.

The magnitude of damage might also change due to other factors as a function of site and time. Some of those characteristics, to mention a few, are a changing number or distribution of the human population (thereby in / decreasing the number of affected people), a changing sensitivity of ecosystems, an application of remediation technologies in the future, and a change in climatic conditions. Steen [27], however, argues that abatement measures should not be considered in LCA because one of the purposes of LCA is to encourage technology development (which will not be done if this is already taken into account in the damage assessment).

In theory, future changes in the magnitude of damages could be considered in the discount rate. However, it seems more reasonable to model such changes in damage in the impact assessment phase prior to discounting. One reason is that the magnitude of damage is usually not an exponential function of time (an exponential relationship is required when discounting with a constant rate, see Equation 1). One way to consider future changes in the magnitude of damage is with a scenario analysis (Section 3).

\subsection{Discounting Environmental Damages because of Pure Time Preference}

In discounting, an important question to be addressed is whether an identical environmental damage can be worth less in the future than today. We will assume that the damage occurs with absolute certainty and that the magnitude of damage is always the same (see example in Table 1).
It is well known that, in actual decision making, people often tend to prefer a present utility to a future utility. Linestone [29] claims that most people have a short planning horizon and that they are really concerned only with their immediate neighborhood in space and time. Many other authors and empirical evidence confirm this view (e.g. [30-33]). People differentiate peoples according to several kinds of distance or proximity (geographical, cultural, and temporal). Deciding about whether one cares more about people in the far future than about current people is a little like deciding whether one cares more about people on one continent than on another, ... or about those with whom one shares history and culture more than those who do not. ... These preferences show up in charitable giving, in foreign aid, in immigration policy, and in military intervention [33]. Behavioral research suggests that many people have a positive discount rate, but that they attach less importance to a difference between two times the further into the future these times are moved. Therefore, the discount rate would be decreasing as a function of time (for quotes see [20]). Discounting because of pure time preference is commonly accepted (though sometimes called irrational), when short-term horizons are concerned. However, in decisions affecting future generations it is ethically questionable.

There seems to be wide agreement among ethicists that the welfare of future generations should be a concern to us and that all members of all generations deserve equal treatment including those not yet born. Only an equal treatment of all people without their temporal position is accepted as morally correct (e.g., $[17,18,31,34-36]$ and the herein quoted authors). A pure time preference with a positive value implies that future people are not moral objects with equal rights as current people [3]. If LCA wants to meet commonly accepted ethical standards, environmental impact harming future generations cannot be subjected to discounting because of pure time preference. According to this line of thinking, we propose setting the pure rate of time preference $\left(r_{\text {pref }}\right.$ in Equation 2) to zero. However, it has to be acknowledged that timing neutrality is at variance with preferences of most current people [20]. Therefore, in practice, decision-makers often have and use a pure rate of time preference greater than zero.

\subsection{Discounting because of capital productivity and diminishing marginal utility of consumption}

Discounting because of capital productivity assumes a relationship between environmental damage and economic values. Therefore, we will first discuss if and how monetary equivalents can be found for environmental damage and what objections exist to the monetarization approach. Afterwards, discounting of the monetary equivalent of environmental damage will be discussed assuming that monetarization is accepted.

\subsubsection{Monetary valuation of environmental damages}

In economics, especially in cost-benefit analysis, it is common practice (though also controversial) to assign prices to external benefits and costs [15]. These prices are called 
shadow prices. In environmental economics it is often suggested that a price be assigned to natural assets via taxes [37] or by distributing a limited amount of pollution rights so that the stock market decides upon the price [38]. The objective is to correct limitations of the market, where nature is not perceived as a scarce resource and, as a consequence, not adequately considered in policy and liability decisions [39]. For instance, a coal-fired power plant can have negative health effects, such as asthma, on the population in the neighborhood. The market does not provide a signal that the plant ought to control its air emissions [40]. Assigning a monetary value to these health effects is one approach to put these external costs on par with other costs and to force the power plant to consider them (polluter-pays-principle).

However, the monetarization of human lives or natural assets is often perceived as unethical (see Leist [31] and references cited therein). MacLean [36] calls it morally repugnant if (human) life is seen as being exchangeable with other utilities. Other authors writing on ethics and especially on economics $[14,15,31]$ agree that natural assets, in fact, do not have a price - but, first, there would probably be a willingness to pay for them if a market existed, and, second, decisions often require a ranking of preferences between incompatible choices. Indeed, there are many examples where an aggregation of different types of damage is common practice, e.g. liability law or extra payments for high-risk jobs [15]. Compensation in liability cases is usually accepted by the involved parties [41]. Also many methods for Life-Cycle Impact Assessment (LCIA) aggregate damages of different nature and therefore suggest the possibility of tradeoffs $[10,27,42-44]$. Fully aggregating methods either use a fictitious unit such as 'points' for measuring an environmental impact $[10,42-44]$ or monetary units $[27,45-47]$. For instance, the external costs of electricity supply in the US were estimated with the help of LCA $[40,48]$. Even if a nonmonetarizing method is applied, financial investments are often compared to the environmental benefits (measured, for instance, in 'points'). Meier [49] defines eco-efficiency as the quotient of the net ecological benefit (LCA result) and the net present value of the investment (Equation 1). Other authors propose to directly convert impact quantified by LCA to monetary units $[13,48,50]$. Therefore, a relation between LCA results and monetary units appears to exist.

The total economic value is composed of the use value, the option value (value for having an option to use something in the future), and the existence value (intrinsic value) [51]. There are various techniques for estimating these external costs, among others market prices (e.g. of crops which cannot grow any more due to an emission), hedonic prices (e.g. the decrease of house prices as a consequence of increasing noise), travel costs (to visit an area), and the contingent valuation method (surveys of the 'Willingness To Accept' (WTA) or the 'Willingness To Pay' (WTP) of people to prevent or accept a damage ${ }^{3}$, e.g. a reduction in mortality risk) $[39,40$,

${ }^{3}$ From a moral perspective, WTA is more suitable than WTP for valuing damages to natural assets (public goods), because this implies that the property rights are held by people (in the present and in the future) [31]
52-56]. These techwiques have frequently been used in policymaking [12,40,52-54,57] and they have widely been discussed in the environmental literature (more than 2,000 papers [54]). However, they have some major shortcomings $[36,40,55,58]$ : One drawback of the WTP approach is that the shadow prices depend on the initial endowments of people without considering the distribution of economic opportunities [21] ('one dollar one vote'). Unless cost/benefit analysis is accompanied by criteria that speak to distributional concerns, there is some danger in using it to identify 'optimal' ... policies [21]. Another limitation is that it is difficult to associate verbal responses to subsequent behavior. Furthermore, it is hardly possible to estimate a proper price for pervasive and complex environmental problems such as the greenhouse effect $[59,60]$. Finally, there is a risk that such price estimations do not include the nonquantifiable element (existence value) such as the value of a species for its own sake [59]. These shortcomings show that monetarization should be applied with caution [59]. Nevertheless, if applied in an adequate context, monetarization techniques may be powerful instruments for the economic and environmental assessment of policy options.

From this discussion, we have concluded that there are good reasons and techniques for a monetarization of environmental damages. However, there are ethical objections towards assigning a price to human life and natural assets presuming exchangeability with marketed goods. Moreover, existing procedures for assigning prices to non-marketed assets are controversial. The following section discusses discounting under the conditions that it is accepted to assign monetary values to environmental damages and that a positive view is held towards the market economy.

\subsubsection{Discounting the monetary value of environmental damage}

One reason for discounting in economics is that capital can usually be invested so that it grows in the future. Put in other words, there is a possibility that reducing current consumption and investing the saved resources can increase future consumption. For instance, assume that there are two persons $A$ and $B$ that have the same amount of money available for investment. A puts the money into a saving box and waits for a year. B invests the money in one sack of corn and plants this corn on a field. After paying part of the harvest for rent, B obtains two sacks of corn one year later. It is obvious that A - though not losing any money - foregoes benefit, because he could have doubled his money as well instead of merely keeping it. The foregone benefit of $A$ is called opportunity cost. Opportunity cost is one reason why discounting is a must in economics. Another argument for discounting in the context of capital productivity is the diminishing marginal utility of consumption. Fconomic growth (related to income) causes people to attach less weight to additional gains and, therefore, discounting is needed. From Equation 2 we deduce that discounting on the basis of capital productivity and diminishing marginal utility of consumption can be done with a positive discount rate in the case of economic growth and with a negative rate in the case of recession. Therefore, the discount rate depends on the ex- 
pectations about the development of the world's economy. These expectations are very controversial. For instance, standard economic analyses assume continuous growth of the economy. However, this assumption has been questioned substantially in the context of limited natural resources and increasing technological risks such as radiation and toxic waste $[59,60]$.

Concerning environmental issues, it seems odd to discount future damage or (dis)utility, as these cannot be stored in a fund, and there is no reason to expect such a fund to grow [60]. Nevertheless, there are arguments that might justify this type of discounting under certain circumstances. Assume, for example, that monetarization is performed on the basis of prevention or abatement costs. Using the prevention cost example of Table 1 , it seems logical to say that discounting might be justified in this scenario. However, this approach has a confidence problem. It is difficult to guarantee that the money will not be consumed by intermediate generations. Moreover, abatement costs do not seem to be an adequate measure in an LCA, where damages are valued considering the magnitude of impact or political targets ${ }^{4}$. The two approaches do not seem to match well. On the contrary, the willingness to pay (WTP) and the willingness to accept (WTA) approaches seem to be applicable for LCA purposes. The WTP approach was used for the EPS method [27] and in the ExternE project [12]. The valuation of some other LCIA methods $[10,43,44]$ is based on panel methods or political targets. It seems reasonable to assume that a damage that receives a high weight by a panel (or politicians representing the people) would also receive a high 'price' if the panel would be asked to assign monetary values.

Applying the WTP or WTA approach implies that damages can be compensated financially. This is usually assumed in cost-benefit analysis. The efficiency criterion of cost-benefit analysis is usually interpreted as making changes that help some, even at the expense of others, as long as the gainers can fully compensate the loosers (Kaldor Hicks criterion) [61]. Since the money for compensation of damages occurring in the long-term could be invested on the capital market, discounting could be justified in these cases (see Table 1). The problem with this approach is twofold. First, future generations cannot be asked whether they agree to such compensations, the decision has to be made by current generations who might be prone to biased decisions. For irreversible damages, no option is left to future generations to choose between the natural asset and the compensation. However, such tradeoffs are already practiced in aggregating LCA, where irreversible and reversible damages are measured on the same

${ }^{4}$ The prevention cost approach has only rarely been used in LCA, for instance by Vogtlander \& Bijma [46]. These authors assume that all measures for prevention will be implemented in the future. However, if this is not the case, the prevention cost approach incites us to prevent the emissions that are most expensive to be prevented (which is questionable from an economical as well as from an environmental point of view). Since LCA usually has the goal to prevent the most harmful impacts, a weighting considering the magnitude of potential damage is the common case. scale (which assumes that tradeoffs are possible). Second, it is not certain that the compensation payment will be passed on by intermediate generations ${ }^{5}[16]$. These ideas can be summarized as follows: discounting can only be justified if it is believed that future generations are adequately compensated and that they would be satisfied with such compensation.

There is one important consequence for the discount rate: If the income per capita increases, the willingness to accept an environmental damage is likely to do so as well. Since both the discount rate and the WTP / WTA are related to economic growth, the resulting overall discount rate might therefore be close or equal to zero $[19,35,63]$. It might even lead to the situation of a negative discount rate: Assume that the WTA for an environmental impact increases over time with the social discount rate (the social discount rate reflects society's relative preferences for consumption in the present and future [64]). For illustrative purposes, we set the elasticity of the marginal utility of consumption to $-2(\eta=2$, Equation 2), the annual rate of economic growth $r_{\text {gro }}=$ annual increase of income $=$ rate of return on investment $=2.3 \%$, and the rate of pure time preference $r_{\text {pref }}=0$. From here, the WTA of 100 Euros in year 0 would grow in value to

$100 *(1+r)^{t}=100 *\left(1+\eta * r_{\text {gro }}\right)^{t}=100 *(1.046)^{t}$ in year $t$.

Let us assume that the compensation money can be invested at $2.3 \%$ (rate of return on investment), so that after $t$ years the available amount would be

$100 *\left(1+r_{\text {gro }}\right)^{\mathrm{t}}=100 *(1.023)^{\mathrm{t}}$

This would lead to a negative overall discount rate of $-2.3 \%$. Price [19], using common utility functions, showed that the overall discount rate might even go towards negative infinity when $\eta>1$. This scenario is plausible considering that constant economic growth over a long period of time would lead to a very high income - and perhaps people would in fact demand an extremely high compensation for damages to natural assets or an increase in mortality risk, because the utility of further money would be limited then, whereas natural assets remain scarce. Above a certain level of income a situation might come up in which no monetary compensation is accepted for any impact to natural assets. These arguments lead to the conclusion that discounting because of the capital productivity could lead to a discount rate close to $0 \%$, even if monetarization of damages and discounting of the monetary equivalent is accepted. However, both positive and negative discount rates also seem to be possible.

\footnotetext{
5 The compensations would not need to be saved in a separate fund - it could also be 'inherited' in another form. For instance, many economists think that the world economy is growing and that the future will be better off than the present [61]. Therefore, future generations could profit from (and be compensated by) greater welfare. However, this expectation presumes sustainable economic growth, since environmental destruction holds all the potential for eroding the capital stock of future generations [62].
} 


\subsection{Discounting because of uncertainties}

Risk or uncertainty about future developments might have an influence on the discount rate. According to Pearce \& Turner [51], the following uncertainties are of relevance:

- Uncertainty about the presence of an individual or society in the future (in the case of long-term emissions)

- Uncertainty about the preferences of the individual (or society)

- Uncertainty about the existence, magnitude, or quality of damage.

There is no doubt that uncertainties exist, especially if time horizons of thousands of years are considered. It is not possible to ascertain whether humankind will still exist and what preferences it will have (see Table 1). It is also unclear whether the predictions of potential environmental impacts are reliable and whether future generations will perceive them as damage. Finally, a new technology could be developed so that longterm damages are eliminated. All these circumstances, if they become reality, would call for a positive discount rate, thereby reducing the present value of any future environmental damage. In fact, such arguments are frequently used in practice. For instance, the opposition towards the decision of the US environmental protection agency (EPA) to consider a 10,000 year horizon without discounting for nuclear waste disposal has been substantial. The criticism was based among other things on the idea that the future state of society is uncertain and that discounting should therefore be done with a positive rate [32]. The question is whether these arguments are strong enough to justify discounting.

There are many ethical objections towards discounting with a discount rate greater than zero because of the uncertainty of the existence of costs. First, uncertainties can be used to justify both positive and negative discount rates [31,34]. For instance, the population number might grow, the population might get more sensitive to environmental pollution, or environmental impacts unforeseen today may appear in the future, thereby increasing the number of people potentially affected. A new remediation technology might be developed, but it might also generate new environmental problems. And even if such a technology could be developed, this does not ethically justify the imposition of risks on the future [34]. Just because $A$ is better able to deal with $B$ 's problems than $B$ is, does not mean that $B$ has the right to impose his problems on $A$ [34]. Second, one of the goals of many LCAs is to prevent environmental harm by identifying key environmental issues and thus stimulate technological development. If we examined scenarios where future technology would solve all environmental problems, we would not get the incitements to develop such technology [27]. Third, uncertainty is not an ethical justification for rejecting responsibility for future generations [31]. If there is a probability for humankind to exist in the future, and this probability is large [60], then current generations automatically have the responsibility not to harm future generations [31]. Even if the state of the future society differs from today's, it is very likely that fatalities, illnesses, and injuries will still be perceived as damages [19,31]. Ethicists argue that the preferences of current society should serve as proxy of future generations [34]. A further argument is that discounting because of the uncertainty of the existence of humankind would encourage a casual attitude to the future, which increases the likelihood of damage to future generations ('self-fulfilling prophecy') [19].

From this discussion we conclude that there are severe objections to discounting because of (1) uncertainty about the presence of a society and (2) about the preference of the society. Since uncertainty (3) concerning the existence of cost might not grow exponentially as a function of time [12], we propose considering this type of uncertainty in the modeling of the magnitude of damage (Section 2.1) rather than in the 'real' discount rate.

\subsection{Conclusions for the Use of Discounting in Environmental Assessment Tools}

From the above sections, several conclusions can be drawn:

- If done sincerely and transparently it is desirable to consider anticipated changes in the magnitude of damage in the nominal discount rate or, better, in a prior phase of impact assessment (thus working with a 'real' discount rate thereafter).

- Ethical considerations lead to the conclusion that discounting because of pure time preference is not acceptable if several generations are involved. Therefore, the term $\mathbf{r}_{\text {pref }}$ in Equation 2 should be set to zero.

- Discounting because of capital productivity might be accepted under several conditions. First, it should be possible to express the damage in monetary units. Second, it should be possible to compensate future generations for the damage. Third, there should be a compelling reason to believe that they would be satisfied with such compensation. All these prerequisites are debatable in case of long-term environmental damages. However, even if discounting because of capital productivity is accepted, the discount rate might be close to zero (positive or negative, the upper limit for any long-term discount rate being the rate of economic growth).

- Uncertainty about the existence of damage could justify positive and negative discount rates. However, it is advisable to consider these uncertainties in the modeling of the damage magnitude rather than to include it in the real discount rate.

In the following section, we will apply discounting to the future impacts of a slag landfill. We will use different discount rates to illustrate their influence on the results.

\section{Case Study: Discounting the Impacts of Heavy Metais Emsissions from Slag Landfills}

The emissions of $\mathrm{Cd}^{2+}$ and $\mathrm{Cu}^{2+}$ from a slag landfill to the groundwater have been quantified as a function of time with the help of a geochemical model [65]. Fig. 2 shows the potential emissions of $\mathrm{Cd}^{2+}$ to the groundwater from a slag

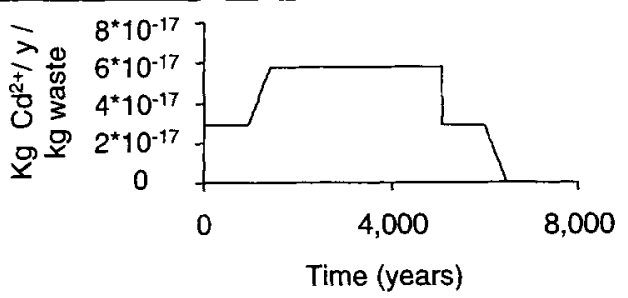

Fig. 2: Emissions of $\mathrm{Cd}^{2+}$ from a slag landfill as a function of time $[65,66]$. The functional unit is the deposition of $200 \mathrm{~g}$ of slag corresponding to the incineration of $1 \mathrm{~kg}$ of waste of an average Swiss composition 
landfill. In order to assess the potential impact of these emissions, the authors have modeled the consequences of a change in the absolute magnitude of damage due to a changing background contamination (Section 2.1). For this purpose, we developed three different scenarios: Our first scenario Trend extrapolates current trends observed in Switzerland and takes account of a possible depletion of resources. The second scenario Free Market is an environmental worst-case scenario assuming first an increase and then a constant use of cadmium and copper. Our last scenario New Values assumes a dramatic reduction of the use of heavy metals. These scenarios served to estimate the total pollution of the Swiss groundwater with heavy metals. This background contamination as a function of time was considered in the weighting of the emissions of Fig. 2. We used the Swiss Method of Ecological Scarcity [44] in the impact assessment (unit: ecopoints). We chose this method in spite of its obsolete character, because it assumes a simple (quadratic) relationship between background pollution and environmental damage, which facilitates the calculation. For a detailed description of the scenarios and the modeling of the background contamination consult [66].

The weighted results are presented in Fig. 3. The differences between the three scenarios are large when the Method of

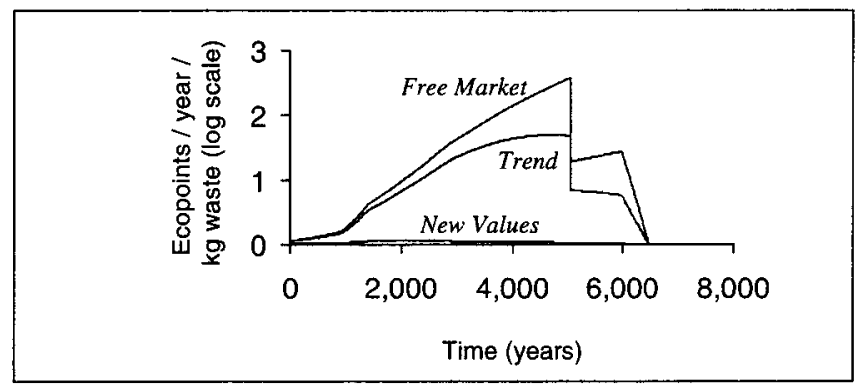

Fig. 3: LCIA results of $\mathrm{Cd}^{2+}$ emissions from slag landfills as a function of time considering potential changes in the background contamination level. The functional unit is the deposition of $200 \mathrm{~g}$ of slag corresponding to the incineration of $1 \mathrm{~kg}$ of waste of an average Swiss composition. The Method of Ecological Scarcity [44] was applied in the impact assessment
Ecological Scarcity is used (note that there would be no difference between them if a linear method such as Eco-indicator 95 [42] had been applied). It can be deduced that the development of the background contamination may have a strong influence on the magnitude of impact. Therefore, scenario analysis about changes in damage magnitude may be recommendable in problem situations, in which a large share of impact occurs in the future and in which non-linear doseresponse curves can be assumed.

As recommended in Sections 2.2 to 2.4, we applied discounting with a slightly positive and slightly negative discount rate $(-1 \% \leq r \leq+1 \%)$. This range of values for the discount rate is plausible when, for example, the pure time preference is set to zero and when uncertainties are not considered in the discount rate. In this case, the value of the discount rate depends on the question, whether monetarization is accepted (if not then $r=0 \%$ ) and what assumptions are made about the future development of the economy and compensation payments (Section 2.3). For illustrative purposes, we also performed the calculations with higher real discount rates of between $r= \pm 5 \%$ and $r= \pm 10 \%$. These high discount rates might incorporate uncertainties, expectations about economic growth and compensation payments, and pure time preference.

Fig. 4 shows the results for $\mathrm{Cd}^{2+}$ as a function of time (in ecopoints per year and $\mathrm{kg}$ waste, left graph) and aggregated over time (right graph) assuming a constant background contamination of the groundwater at the current pollution level in Switzerland. Note the application of a different impact assessment method would only change the unit of the $y$-axis. The table in Fig. 4 additionally shows the discounted results for the three scenarios described above. The importance of long-term emissions is reduced considerably if positive discount rates are applied. At a discount rate of $+5 \%$ all impacts after about 200 years are reduced to less than $0.005 \%$ compared to the rating without discounting. At a discount rate of $+1 \%$, the time horizon considered increases to about 1,000 years. The use of negative discount rates

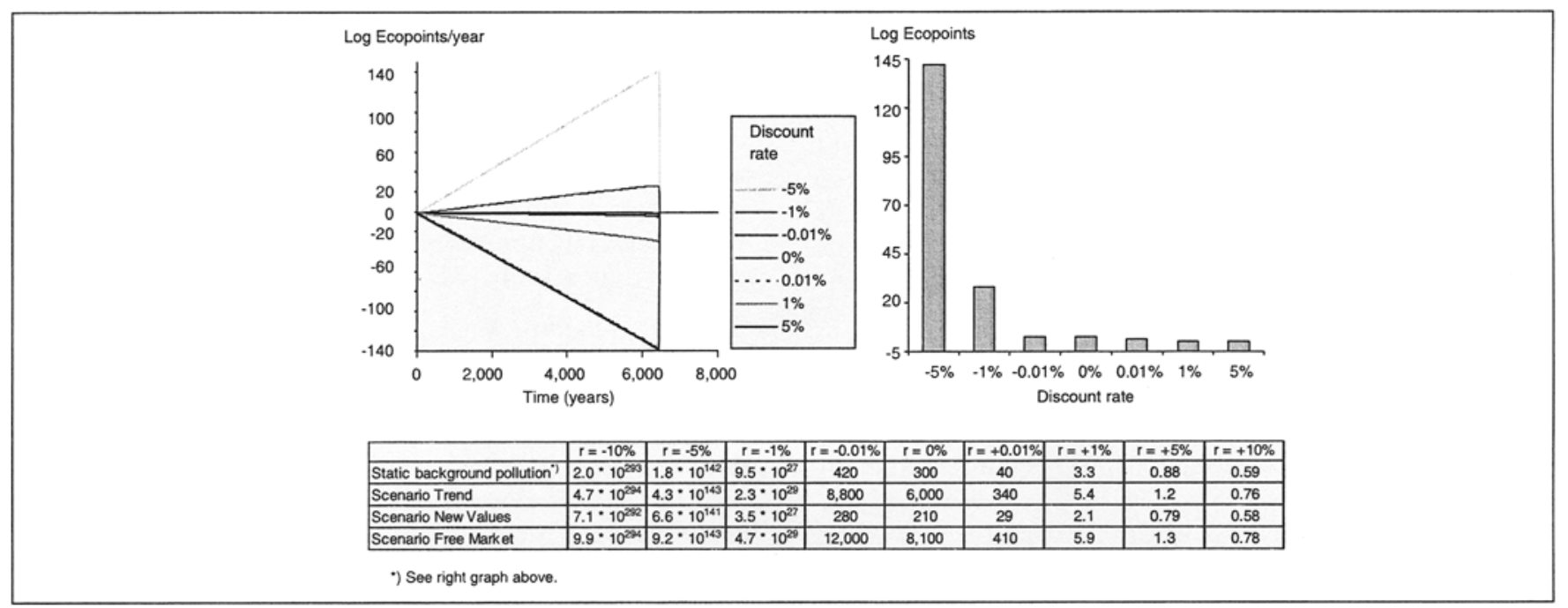

Fig. 4: LCIA results for $\mathrm{Cd}^{2+}$ emissions from slag landfills to the groundwater using different discount rates (Method of Ecological Scarcity). The left graph displays impact as a function of time (impact per year and $\mathrm{kg}$ waste) assuming a constant background contamination. The right graph shows the same results aggregated over time. The table below displays the aggregated numerical values in ecopoints concerning static (compare graph above) and variable background contamination levels modeled with scenario analysis 
leads to extremely high results in the case of heavy metal emissions from slag landfills due to the long emission period of several thousands of years (Fig. 4). By contrast, the overall score is reduced to a value close to zero if a discount rate of $+1 \%$ or higher is used. The higher the discount rate, the smaller are the differences between the three scenarios assumed (see table in Fig. 4). The exponential nature of discounting makes it so strong concerning long-term impacts, that all other influencing factors appear small.

If we extend the system boundaries to the impacts from waste incineration including the above effects from slag landfills, we find that the importance of the process step 'slag landfill' depends completely on the discount rate applied. Without discounting, the emissions from the slag landfills have a higher impact score than the complete remaining system (between 210 and 8,100 ecopoints for $\mathrm{Cd}^{2+}$ and between 4,000 and 14 million ecopoints $\mathrm{Cu}^{2+}$ emissions, Fig. 4). In comparison, the remaining system (without slag landfills) consisting of the incineration of waste, transport, infrastructure, production of ancillary products, and deposition of filter ash in subsurface salt mines would receive a rating of between 590 and 1,120 ecopoints per $\mathrm{kg}$ waste incinerated (in the former case, credit was given for the energy produced; reference system: European electricity and heat production from oil). Discounting with a positive rate of, e.g. $r=+1 \%$ makes the impact of the slag emissions small in comparison to the remaining system (between 2 and 6 ecopoints for $\mathrm{Cd}^{2+}$ and between 19 and 42 ecopoints for $\mathrm{Cu}^{2+}$. Applying negative discount rates leads to an extremely high impact of the slag landfills compared to the remaining system. Therefore, the answer to the question which process step is the key problem of waste incineration completely depends on the discount rate. Similarly, in an LCA comparing various waste treatment processes, the technology ranking depended entirely on the discount rate [72].

\section{Discussion and Conclusions}

One of the prerequisites for discounting is the availability of temporally differentiated data. So far, only few attempts have been undertaken to provide such data in the inventory analysis $[65,67]$. The provision of emission patterns as a function of time is complicated work and, therefore, it is likely that it remains restricted to cases where time plays a central role (e.g., because of a long emission period). If temporally differentiated data is available, the technical application of discounting is easy. However, the appropriateness of discounting is a controversial issue.

It is often claimed that discounting contradicts sustainability. In fact, with sufficiently long time horizons, the value of future damages becomes negligible when positive discount rates are applied. Discounting has not been integrated into the EPS method because it was regarded as being incompatible with the principle of the Rio Convention that future generations have the same right to a good environment as current generations [27]. While we agree with this statement as such and, therefore, suggest setting the pure rate of time preference to zero, we oppose to banish the complete concept of discounting because of this reasoning. There is a strict and a soft interpretation of sustainability [31] and this differentiation is crucial with respect to discounting. According to the strict interpretation ('strong sustainability'), nature should remain as it is - therefore discounting would be prohibited. According to the soft interpretation ('weak sustainability'), substitutability between different kinds of resources is allowed [68]. Therefore, compensation payments could be sufficient, allowing the use of discounting principles (Section 2.3). However, it should be noted that these principles could result in a neutral, positive, or negative discount rate depending on the growth rate of income, rate of return on investment, elasticity of marginal utility of consumption, and, in some models [19], on the period of analysis and size of compensation in relation to income.

While discounting is generally accepted in intragenerational issues, ethicists agree that there should not be intergenerational discounting because of pure time preference. Ironically, the actual practice in LCA is often exactly the opposite. While discounting is often performed at time horizons beyond 100 years (with an indefinitely high discount rate in the case of a temporal cut-off), the emissions or impacts occurring during the first 100 years are usually fully considered (with a $0 \%$ discount rate). This practice is easily understandable, as it has empirically been shown that most people are more concerned with people they know than with generations of the far future (Section 2.2). The question, however, is whether LCA wants to satisfy such preferences or whether it wants to meet commonly accepted ethical standards, and these two principles diverge drastically in the question of intergenerational discounting because of pure time preference. In this paper, we argue in favor of the 'ethical' solution of treating all safeguard subjects equally in (place and) time. However, we realize that actual decisions are often shaped by personal preferences for people that are closer to us in place and time. The application of discounting and the determination of the discount rate will remain as to be value choices [3].

Hofstetter $[69,70]$ used cultural theory for a definition of various archetypes with different value systems and applied this concept to the impact assessment of LCA. This approach could also be used to structure the discussion of discounting. In the following, we determine which discount rate would fit to the three archetypes (hierarchist, individualist, and egalitarian) used in $[69,70]$. Note that the archetypes are only indicative, theoretical constructions. In practice, worldviews rely upon combinations of such perspectives and develop dynamically [71].

The first archetype, the hierarchist, considers future generations to be as important as current generations. In our analysis, we assumed a view similar to the hierarchist perspective (as recommended by Goedkoop et al. [10]). This archetype does not have a pure time preference and would apply a discount rate of close or equal to $0 \%$. However, even such small discount rates below $1 \%$ might influence the results considerably, as our example has shown (Section 3). At a rate of $1 \%$, all emissions after 1,000 years become irrelevant. Using a smaller rate of $0.01 \%$ increases the time horizon considered to about 100,000 years. Negative discount rates inflate the results to very high values if long-term time 
horizons are considered such as in our case study for $\mathrm{Cd}^{2+}$ emissions from landfills. The application of the other archetypes would lead to even more extreme results. The individualist believes in the self-regulatory forces of the market and in the benign behavior of nature. This archetype might assume a scenario similar to our scenario Free Market. An individualist would advocate monetarization and discounting at the private discount rate (note that this perspective could be considered unethical concerning intergenerational issues). The discount rate of the financial market is typically $+5 \%$ to $+7 \%$ per year in the European Community [12], but private companies use discount rates much higher than that. At discount rates of $+5 \%$ and $+20 \%$, all impacts after 205 and 55 years, respectively, are virtually neglected (less than $0.005 \%$ compared to the rating without discounting). As a consequence, an individualist would see no reason for precautionary measures, e.g. implementing new technologies that try to reduce the long-term emissions. The egalitarian assigns more weight to the future than to the present. He prefers a preventive management that reflects the precautionary principle [70]. An egalitarian would prefer our scenario New Values (although he might expect a more pessimistic development) and would apply a zero or even a negative discount rate. This application of a negative discount rate would lead to an extremely high damage even with respect to the environmentally positive scenario of New Values. Therefore, an egalitarian would consider current incineration technologies environmentally very harmful due to the long-term emissions of slag landfills (Section 3). However, applying a negative discount rate, he would even think worse of technologies used for vitrifying the slag and, therefore, prolonging the emission period. Recovering the heavy metals would be the only accepted way of waste treatment in this case.

While this paper can provide some assistance for deciding upon the discount rate, the ultimate choice concerning the discount rate remains a value-laden question [3]. However, it can be stated that the long-term discount rate should be close or equal to zero if LCA wants to meet common ethical standards. In our opinion, it is advisable to perform a sensitivity analysis when future environmental impacts are involved. Concerning long-term effects, the sensitivity analysis should consider at least three different discount rates: a zero rate as well as a slightly positive and negative rate. If the results are sensitive to the choice of the discount rate such as in the case study presented in this paper, a thorough reasoning should be given, why a certain discount rate was chosen.

Acknowledgements. We thank Dr. Thomas Baumgartner, Dr. Martin Scheringer, and two anonymous reviewers for their valuable feedback to an earlier version of this article. The financial support of the Swiss National Science Foundation is gratefully acknowledged.

\section{References}

[1] Hofstetter P (1996): Time in LCA. In: Braunschweig A, Förster, R, Hofstetter, P, Müller-Wenk R, eds. Developments in LCA Valuation, St. Gallen, Switzerland: IWOE - Diskussionsbeitrag Nr 32

[2] Lalive d'Epinay AE (2000): Die Umweltverträglichkeit als eine Determinante des architektonischen Entwurfs. PhD thesis, ETH Zurich, No 13610 , Zurich
[3] Finnveden G (1997): Valuation Methods Within LCA - Where are the Values? Int J LCA 2 (3) 163-169

[4] Heijungs R, Huppes G (1999): Inventory Modelling in the Dutch LCA Methodology Project. In: Guinée J, eds. Danish-Dutch Workshop on LCA Methods. Leiden (NL)

[5] Nielsen PH, Hauschild M (1998): Product Specific Emissions from Municipal Solid Waste Landfills; Part I: Landfill Model. Int J LCA 3 (3) $158-168$

[6] Guinèe JB, eds. (1999): Danish-Dutch Workshop on LCA Methods, CML Leiden (NL)

[7] Sundqvist J-O (1998): Life Cycle Assessment and Solid Waste: A Guideline for Handling Waste Disposal in LCA. Draft Version, Stockholm: Swedish Environmental Protection Agency

[8] Huijbregts MAJ, Guinèe JB, Reijnders L (2001): Priority Assessment of Toxic Substances in the Frame of LCA. III: Export of Potential Impact over Time and Space. Chemosphere 44, 59-65

[9] Hertwich EG, Mateles SF, Pease WS, Mckone TE (2001): Human Toxicity Potentials for Life-Cycle Assessment and Toxics; Release Inventory Risk Screening. Environmental Toxicology and Chemistry 20 (4) 928-939

[10] Goedkoop M et al. (1999): The Eco-indicator 99: A Damage Oriented Method for Life Cycle Impact Assessment. Methodology Report, Amersfoort: Pré Consultants

[11] Rabl A, Spadaro JV, McGavran PD (1998): Health Risks of Air Pollution from Incinerators: A Perspective. Waste Manage Res 16 (4) $365-388$

[12] European Commission (1995): ExternE: Externalities of Energy. Luxembourg: Office for Official Publications of the European Communities

[13] Norris GA (2001): Integrating Life Cycle Cost Analysis and LCA. Int J LCA 6 (2) 118-120

[14] van Beukering P, Ooosterhuis F, Spaninks F (1998): Economic Valuation in Life Cycle Assessment. Applied to Recycling and Solid Waste Management. Working Paper, W98/02, Amsterdam: Institute for Environmental Studies. Vrije Universität

[15] Pearce DW (1983): Cost-Benefit Analyses. London: The Macmillan Press LTD

[16] Lind RC (1990): Reassessing the Government's Discount Rate Policy in Light of New Theory and Data in a World Economy with a High Degree of Capital Mobility. Journal of Environmental Economics and Management 18, S8-S28

[17] Livingstone I, Tribe M (1995): Projects with Long Time Horizons: Their Economic Appraisal and the Discount Rate. Project Appraisal 10 (2) 66-76

[18] Azar C, Sterner T (1996): Discounting and Distributional Considerations in the Context of Global Warming. Ecological Economics $19,169-184$

[19] Price C (2000): Discounting Compensation for Injuries. Risk Analysis 20 (6) 839-849

[20] Harvey CM (1994): The Reasonableness of Non-Constant Discounting. Journal of Public Economics 53, 31-51

[21] Howarth RB, Norgaard RB (1995): Intergenerational Choices under Global Environmental Change. In: Bromley DW, eds. Handbook of Environmental Economics, Oxford: Blackwell, 111-138

[22] Udo de Haes HA (1999): ISO's Compromise on Comparative Assertions in Life Cycle Impact Assessment. Journal of Industrial Ecology 2 (3) 4-7

[23] van Ark B (1997): Economic Growth in the Long Run: A History of Empirical Evidence. Groningen: Elgar Reference Collection

[24] Rabl A (1999): Who Pays What as Function of Discount Rate in Intergenerational Cost-Benefit Analysis: the Example of Nuclear Power. Internal Working Paper, Paris: Ecole des Mines

[25] Potting J, Schöpp W, Blok K, Hauschild M (1998): Site-Dependent Life-Cycle Impact Assessment of Acidification. Journal of Industrial Ecology 2 (2) 63-87

[26] Anonymous (1997-99): ISO 14040-43. B-Brüssel: European Committee for Standardization (CEN)

[27] Steen B (1999): A Systematic Approach to Environmental Priority Strategies in Product Development (EPS). Version 2000 - Gen- 
eral System Characteristics. Stockholm (S): Centre for Environmental Assessment of Products and Material System; Chalmers University of Technology

[28] Potting J, Hauschild M (1997): Predicted Environmental Impact and Expected Occurrence of Actual Environmental Impact: The Linear Nature of Environmental Impact from Emissions in LifeCycle Assessment. International Journal of LCA 2 (3) 171-177

[29] Linestone HA (1973): On Discounting the Future. Technological Forecasting and Social Change 4, 335-338

[30] Ahearne JF (2000): Intergenerational Issues Regarding Nuclear Power, Nuclear Waste, and Nuclear Weapons. Risk Analysis 20 (6) $763-770$

[31] Leist A (1996): Ökologische Ethik II: Gerechtigkeit, Ökonomie, Politik. In: Nida-Rümelin J, eds. Angewandte Ethik. Die Bereichsethiken und ihre theoretische Fundierung, Stuttgart: Kröner, 386-457

[32] Okrent D (1999): On Intergenerational Equity and Its Clash with Intragenerational Equity and on the Need for Policies to Guide the Regulation of Disposal of Wastes and Other Activities Posing Very Long-Term Risks. Risk Analysis 19 (5) 877-900

[33] Schelling TC (2000): Intergenerational and International Discounting. Risk Analysis 20 (6) 833-837

[34] Shrader-Frechette (2000): Duties to Future Generations, Proxy Consent, Intra- and Intergenerational Equity: The Case of Nuclear Waste. Risk Analysis 20 (6) 771-778

[35] Birnbacher D (1989): Intergenerationelle Verantwortung oder: Dürfen wir die Zukunft der Menschheit diskontieren? In: Kümmel R, Klawitter, J, eds. Umweltschutz und Marktwirtschaft aus der Sicht unterschiedlicher Disziplinen, Würzburg, 101-115

[36] MacLean DE (1990): Comparing Values in Environmental Policies: Moral Issues and Moral Arguments. In: Hammond PB, Coppock, R, eds. Valuing Health Risks, Costs, and Benefits for Environmental Decision Making, Washington: National Academy Press, 83-106

[37] Baumol WJ, Oates WE (1971): The Use of Standards and Prices of Protection of the Environment. Swedish Journal of Economics $73,42-54$

[38] Tietenberg T (1990): Economic Instruments for Environmental Regulation. Oxford Review of Economic Policy 6

[39] Bockstael NE et al. (2000): On Measuring Economic Value. Environmental Science and Technology 34 (8) 1384-1389

[40] Matthews HS, Lave LB (2000): Applications of Environmental Valuation for Determining Externality Costs. Environmental Science and Technology 34 (8) 1384-1389

[41] Berg $M$ et al. (1994): Was ist ein Schaden? Zurich: vdf

[42] Goedkoop M (1995): The Eco-indicator 95 - Weighting Method for Environmental Effects that damage Ecosystems or Human Health on a European Scale. Amersfoort: Novem

[43] Hauschild M, Wenzel H (1997): Environmental Assessment of Products; Scientific Background. London: Chapman \& Hall

[44] SAEFL (1998): Bewertung in Ökobilanzen mit der Methode der ökologischen Knappheit. Ökofaktoren 1997. SRU-297, Bern: Swiss Agency for the Environment, Forests and Landscape

[45] Johansson J (1999): A Monetary Valuation Weighting Method for Life Cycle Assessment Based on Environmental Taxes and Fees. Master Thesis, Stockholm University, Sweden

[46] Vogtlander JG, Bijma, A (2000): The 'Virtual Pollution Prevention Costs ' 99 '. Int J LCA 5 (2) 113-124

[47] Vogtlander JG, Brezet, HC, Hendriks, CF (2001): The Virtual EcoCosts '99. Int J LCA 6 (3) 157-166

[48] Shapiro KG (2001): Incorporating Costs in LCA. Int J LCA 6 (2) 121-123

[49] Meier M (1997): Eco-Efficiency Evaluation of Waste Gas Purification Systems in the Chemical Industry. $\mathrm{PhD}$ thesis, ETH Zurich, No 12259, Zurich

[50] Frischknecht R (1998): Life Cycle Inventory Analysis for Decision-Making. PhD thesis, ETH Zurich, No 12599, Zurich
[51] Pearce DW, Turner R (1990): Economics of Natural Resources and the Environment. London: Harvester Wheatsheaf

[52] Pearce DW, Seccombe-Hett T (2000): Economic Valuation and Environmental Decision-Making in Europe. Environmental Science and Technology 34 (8) 1419-1425

[53] Hammitt JK (2000): Valuing Mortality Risk: Theory and Practice. Environmental Science and Technology 34 (8) 1396-1400

[54] Carson RT (2000): Contingent Valuation: A User`s Guide. Environmental Science and Technology 34 (8) 1413-1418

[55] Spash CL (2000): Multiple Value Expression in Contingent Valuation: Economics and Ethics. Environmental Science and Technology 34 (8) 1433-1437

[56] Fischhoff B (2000): Informed Consent for Eliciting Environmental Values. Environmental Science and Technology 34 (8) 1439-1444

[57] Mourato S, Ozdemiroglu E, Foster V (2000): Evaluating Health and Environmental Impacts of Pesticide Use: Implications for the Design of Ecolabels and Pesticide Taxes. Environmental Science and Technology 34 (8) 1456-1461

[58] Sagoff M (2000): Environmental Economics and the Conflation of Value and Benefit. Environmental Science and Technology 34 (8) 1426-1431

[59] Allenby BR (1999): Industrial Ecology; Policy Framework and Implementation. Upper Saddle River: Prentice Hall

[60] Daly HE, Cobb JB (1989): For the Common Good; Redirecting the Economy Toward Community, the Environment, and a Sustainable Future. Boston: Beacon Press

[61] Page T (1977): Conservation and Economic Efficiency. Baltimore: John Hopkins University Press

[62] Pearce DW (1983): Ethics, Economics and the Environment. International Journal of Environmental Studies 21, 1-3

[63] Rabl A (1996): Discounting of Long-Term Costs: What would Future Generations prefer us to do? Ecological Economics 17, $137-145$

[64] Hammitt JK, Harvey CM (2000): Equity, Efficiency, Uncertainty, and the Mitigation of Global Climate Change. Risk Analysis 20 (6) $851-860$

[65] Hellweg S, Hofstetter TB, Hungerbühler K (2002): Modeling Waste Incineration for Life Cycle Inventory Analysis in Switzerland. Environmental Modeling and Assessment 6 (4) 219-235

[66] Hellweg S, Hofstetter TB, Hungerbühler K (JAHR): Time-Dependent Life-Cycle Assessment of Emissions from Slag Landfills with the Help of Scenario Analysis. Subrnitted to Journal of Cleaner Production

[67] Field F, Kirchain R, Clark J (2001): Life-Cycle Assessment and Temporal Distributions of Emissions. Journal of Industrial Ecology 4 (2) 71-91

[68] Häberli R, Gessler R, Grossenbacher-Mansuy W, Lehmann Pollheimer D (2002): Vision Lebensqualität; Nachhaltige Entwicklung: Oekologisch notwendig, wirtschaftlich klug, gesellschaftlich möglich. Zurich: v/d/f Hochschulverlag AG

[69] Hofstetter P (2000): Modelling the Valuesphere and the Ecosphere: Integrating the Decision Makers' Perspectives into LCA. Int J LCA 5 (3) $161-175$

[70] Hofstetter P (1998): Perspectives in Life Cycle Impact Assessment: A Structured Approach to combine Models of the Technosphere, Ecosphere and Valuesphere. Kluwers Academic Publishers

[71] Janssen M, Rotmans, J (1995): Allocation of Fossil $\mathrm{CO}_{2}$ Emission Rights Quantifying Cultural Perspectives. Ecological Economics $13,65-79$

[72] Hellweg S, Doka G, Finnveden G, Hungerbühler K (2002): Waste and Ecology: Which Technologies Perform Best? In: Ludwig C, Hellweg S, Stucki S, eds. Municipal Solid Waste Management; Strategies and Technologies for Sustainable Solutions, BerlinHeidelberg-New York: Springer

Received: October 1st, 2001 Accepted: September 13th, 2002 OnlineFirst: September 16th, 2002 